\title{
Editorial
}

\section{Clinimetric Dilemmas in Outcome Scales for Mental Disorders}

\author{
Per Bech \\ Psychiatric Research Unit, Mental Health Centre North Zealand, University of Copenhagen, Hillerød, Denmark
}

In the mid-1950s, before the era of psychopharmacological drugs, Parloff et al. [1] designed an outcome scale by which all neurotic patients and all forms of psychotherapy could be clinimetrically compared. The items in this Hopkins Symptom Checklist (SCL) were selected to measure both bodily and mental distress, covering the symptoms people presented when seeking help at the outpatient clinic for psychotherapy at the University Hospital in Baltimore. In its original version the SCL contained 41 items (SCL-41). These were published by Bech [2] with permission from Jerry Frank. Over the 2 decades from 1954 to 1973 the SCL was enlarged to cover states of phobia, obsessive-compulsive states, depression, anxiety, and panic. The ultimate version, SCL-90 [3], thus covered the psychopathological symptoms of the ordinary mental disorders (anxiety, depression, mania, and schizophrenia) but still had as its basic structure bodily distress or somatization, and emotional distress or interpersonal sensitivity.

At the start of the psychopharmacological era in the 1960s, clinician-rated scales were preferred, as these were seen as fulfilling the requirements of the authorities for approval of the new antianxiety, antidepressant, or antipsychotic drugs. In this respect two Hamilton scales were developed - the Hamilton Depression Scale (HAM-D) [4] and the Hamilton Anxiety Scale (HAM-A) [5] - as well as the Brief Psychiatric Rating Scale (BPRS) [6] that covered the outcome measure of patients with ordinary mental disorders.

It was expected that the DSM-5 [7] would adopt the self-reported SCL-90 and the clinician-reported HAM-D, HAM-A, and BPRS [8], but the editors of the DSM-5 found that the dimensional approach was too complicated, probably due to a lack of clinimetric understanding.

Another dimensional instrument was also seriously considered by the editors of the DSM-5, namely the Patient-Reported Outcome Measurement Information System (PROMIS), according to Greenberg [9]. The US National Institute of Health lay behind the PROMIS in an attempt to provide access to health outcomes in both somatic disorders and mental disorders, including psychosomatic disorders. PROMIS covers 5 health domains: physical functioning, social functioning, emotional distress, pain, and fatigue. The items are selected from these domain banks. For example, in the domain of emotional distress items measuring anxiety and depression are to be found in a bank from which the researcher can select items ordered according to the severity location of the dimension under measurement. This ordering of severity is based on clinimetric item response theory models [10]. However, the editors of the DSM-5 rejected PROMIS due to lack of sufficient evidence [9]. Another candidate for health outcome measures of somatic and mental disorders was developed by the International Consortium for

\section{KARGER}

E-Mail karger@karger.com

www.karger.com/pps
C 2016 S. Karger AG, Basel

0033-3190/16/0856-0323\$39.50/0
Per Bech

Psychiatric Research Unit, Mental Health Centre North Zealand

University of Copenhagen, Dyrehavevej 48

DK-3400 Hillerød (Denmark)

E-Mail Per.bech@ regionh.dk 
Health Outcomes Measurement (ICHOM) [11]. The ICHOM domain of emotional distress lists a Standard Set for Depression and Anxiety which includes a battery of scales. However, many of these are diagnostic screening scales rather than clinimetrically valid easy-to-use outcome scales.

The Psychosocial Index (PSI) actually contains easyto-use subscales [12], covering psychosomatic components such as stress, coping with stress, symptoms of anxiety and depression, abnormal illness behavior, and health-related quality of life. It seems clinimetrically relevant to compare the PSI with the banks of items from existing internationally well-accepted scales such as the SCL-90, HAM-D, HAM-A, and BPRS, including the easyto-use WHO-5 well-being scale and the side effect of treatment scale [13]. In this clinimetric comparison we need, however, to take the following dilemmas into account.

\section{Self-Reported versus Clinician-Reported Scales}

When constructing the first version of the SCL, the SCL-41, Parloff et al. [1] considered the components of bodily and emotional distress to be so subjective that 'no one can judge it but the patient'. This statement is also valid for the WHO-5 Quality of Life Scale [14]. On the other hand, in measurement-based care, which is ideally based on a collaborative contact between the therapist and his or her patient, the drug-related outcome is typically clinician-reported. Thus, in the STAR*D study of measurement-based care in depressed patients receiving antidepressive medication, Trivedi et al. [15] used the HAM-D as the primary outcome measure. In the PSI an attempt at collaboration between the therapist and his or her patient is established as the clinician makes a global rating based on the self-reported components.

\section{Brief versus Comprehensive Scales}

In the practical outcome evaluation plan it is essential for both therapist and patient to have easy-to-use scales because in the practical routine each clinic visit has a duration of less than $15 \mathrm{~min}$ [8]. These brief scales are conventionally derived from longer versions used in clinical research, because it is important to compare the results from the practical work with the results obtained in controlled trials on which the treatment has been approved by the authorities. From the SCL-90 we have brief subscales for interpersonal sensitivity, somatization, anxiety and depression, clinimetrically selected by item response theory models [16]. From the HAM-D we have the HAM-D 6 and from the HAM-A the HAM-A $\mathrm{A}_{6}$ [13]. In the PSI valid subscales covering the different domains are indicated.

\section{Binary versus Continuous Likert Items}

When using brief scales, it is clinimetrically preferable to have Likert scales as continuous item quantifiers. In the WHO-5, frequency over the past 2 weeks is the quantifier and is defined on a Likert scale from 0 (at no time) to 5 (all of the time). On the SCL scales the items are measured on an intensity quantifier in which the Likert scale goes from 0 (not at all) to 4 (extremely), which is also the case for the PSI.

\section{Positively versus Negatively Worded Items}

In the WHO-5 the items measure positive well-being and are positively worded, whereas the items in the SCL90 measure negative symptoms and are therefore negatively worded. In many scales, items worded in opposite directions are used, implying that some of the items have to be reversed in the scoring process [13]. According to De Vellis [17] the disadvantages of items worded in opposite directions outweigh any benefits clinimetrically.

\section{Discriminatory versus Predictive Validity}

In outcome scales the ability to discriminate between patients and controls is the most important criterion-related validity index. The SCL-90 and the PSI on the one hand and the HAM- $\mathrm{D}_{6}, \mathrm{HAM}-\mathrm{A}_{6}$, and $\mathrm{BPRS}_{6}$ on the other hand have all been shown to possess an adequate discriminatory validity.

In the PSI, the subscale measuring abnormal illness behavior focuses on the ability to predict response to treatment. Thus, Mechanic [18] considers illness behavior to be an important predictor of how patients adhere to medical advice and of the course of illness, including response to treatment. Sirri et al. [19] have, among the patient-related variables within illness behavior, identified neuroticism as significantly associated with low adherence to medical treatment. Within mental disorders the Eysenck Neuroticism Scale has been shown to have predictive validity both in studies with anxiety disorder [20] and in studies with depression [21]. The type A be- 
havior considered to be a personality trait associated with medical conditions [22] should be regarded as part of the Eysenck extraversion dimension [23, 24].

\section{Unidimensional versus Multidimensional Scales}

When summing up all items into a single score, the items have to reflect one single dimension of severity on which the items are located, in a rank-ordered structure [13]. The original version of the SCL, the SCL-41, was actually designed as a unidimensional scale measuring distress or discomfort. Thus, Parloff et al. [1] stated that the total score of the 41 items would show improvement due to treatment if there was a net decline in the intensity of each individual item. The full SCL-90 version was tested by Derogatis et al. [3] by factor analysis, which identified 9 factors: somatization, obsession-compulsive states, interpersonal sensitivity, depression, anxiety, anger-hostility, phobic anxiety, paranoid ideation, and psychoticism. This factor analytic study performed by Derogatis et al. [3] has been criticized in many studies, that of Vassend and Skrondal [25] being the most important. Whereas somatization and interpersonal sensitivity correspond to the original SCL-41, the factor of obsessive-compulsive states includes many clinically unspecific items. From a clinimetric point of view we need to start with the clinically meaningful subscales and investigate the unidimensional scalability through item response theory models. In a general population study [16] and a clinical study [26] we found the somatization subscale to have borderline acceptability from a clinimetric point of view, while the subscale of interpersonal sensitivity was clearly acceptable. Clinically, we selected the anxiety items to cover Freud's concept of 'Die gemischte Neurose', covering generalized anxiety, panic, phobia, and obsessive-compulsive states. The resulting 8-item SCL anxiety subscale had a high scalability, as did the 6-item SCL depression subscale corresponding to the HAM- $\mathrm{D}_{6}$.
The full HAM-D (HAM- $\left.\mathrm{D}_{17}\right)$ is multidimensional like the SCL-90, but the HAM- $\mathrm{D}_{6}$ is unidimensional [13]. The items in the PROMIS have undergone a careful evaluation for unidimensionality. The items in the various domains are considered as item banks from which the user can select his or her scale [27].

\section{Measuring Response (Effect Size) versus Remission Rates (Number Needed to Treat)}

In the large National Institute of Mental Health outcome measure project, the change during the therapeutic intervention from baseline to endpoint was the conventional improvement measure, either as a $50 \%$ reduction of scale score or in terms of effect size statistics [28]. However, Rush et al. [29] recommended evaluating the percentage of patients remitted at endpoint with a concomitant reporting of the number needed to treat because this is much more relevant and understandable than differences between groups in terms of changes from baseline to endpoint in overall symptom severity. When calculating remission rates, we need to have valid cutoff scores on the rating scales. When establishing the HAM- $\mathrm{D}_{17}$ cutoff score for remission, correspondence to a clinical global assessment below mild depression is recommended [30]. When using self-reported questionnaires such as the SCL-90 subscales or the WHO-5 Well-Being Index, mean scores for the general population studies are employed $[14,16]$. The PSI has via the global observer ratings an acceptable cutoff score to indicate remission, in contrast to the PROMIS or the ICHOM battery of scales.

In conclusion, outcome scales for mental disorders ensure that when working with different treatment orientations, both researchers and ordinary clinicians are able to compare and integrate the results [30]. The PSI should be considered as such a scale. The other outcome scales referred to here should be considered, not as rivals, but as convergent solutions.

\section{References}

1 Parloff MB, Kelman HC, Frank JD: Comfort, effectiveness, and self-awareness as criteria of improvement in psychotherapy. Am J Psychiatry 1954;111:343-352.

2 Bech P: Rating Scales for Psychopathology, Health Status and Quality of Life. A Compendium on Documentation in Accordance with the DSM-III-R and WHO Systems. Berlin, Springer, 1993.
3 Derogatis LR, Lipman RS, Covi L: SCL-90: an outpatient psychiatric rating scale-preliminary report. Psychopharmacol Bull 1973;9: 13-28.

4 Hamilton M: A rating scale for depression. J Neurol Neurosurg Psychiatry 1960;23:56-62.

5 Hamilton M: Diagnosis and rating of anxiety. Br J Psychiatry (spec publ) 1969;3:76-79.

6 Overall JE, Gorham DR: The Brief Psychiatric Rating Scale. Psychol Rep 1962;10:799-812.
Clinimetric Dilemmas in Outcome Scales for Mental Disorders
Psychother Psychosom 2016;85:323-326 DOI: $10.1159 / 000448810$ 
7 American Psychiatric Association: Diagnostic and Statistical Manual of Mental Disorders, ed 5 (DSM-5). Washington, American Psychiatric Association, 2013.

8 Paris J: The Intelligent Clinician's Guide to the DSM-5. Oxford, Oxford University Press, 2013.

9 Greenberg G: The Book of Woe. New York, Penguin, 2013.

10 Cella D, Riley W, Stone A, Rothrock N, Reeve B, Yount S, Amtmann D, Bode R, Buysse D, Choi S, Cook K, Devellis R, DeWalt D, Fries JF, Gershon R, Hahn EA, Lai JS, Pilkonis P, Revicki D, Rose M, Weinfurt K, Hays R; PROMIS Cooperative Group: The PatientReported Outcomes Measurement Information System (PROMIS) developed and tested its first wave of adult self-reported health outcome item banks: 2005-2008. J Clin Epidemiol 2010;63:1179-1194.

11 ICHOM: International Consortium for Health Outcomes Measurement (ICHOM), 2016. http://www.ichom.org/ (accessed June 28, 2016).

12 Piolanti A, Offidani E, Guidi J, Gostoli S, Fava GA, Sonino N: Use of the Psychosocial Index (PSI), a sensitive tool in research and practice. Psychother Psychosom 2016;85:337-345.

13 Bech P: Clinical Psychometrics. Oxford, Wiley-Blackwell, 2012.

14 Topp CW, Ostergaard SD, Sondergaard S, Bech P: The WHO-5 Well-Being Index: a systematic review of the literature. Psychother Psychosom 2015;84:167-176.

15 Trivedi MH, Rush AJ, Wisniewski SR, Nierenberg AA, Warden D, Ritz L, Norquist G, Howland RH, Lebowitz B, McGrath PJ, Shores-Wilson K, Biggs MM, Balasubramani
GK; Fava M, STAR*D Study Team: Evaluation of outcomes with citalopram for depression using measurement-based care in STAR*D: implications for clinical practice. Am J Psychiatry 2006;163:28-40.

16 Carrozzino D, Vassend O, Bjorndal F, Pignolo C, Olsen LR, Bech P: A clinimetric analysis of the Hopkins Symptom Checklist (SCL90-R) in general population studies (Denmark, Norway, and Italy). Nord J Psychiatry 2016;70:374-379.

17 De Vellis PF: Scale Development. Theory and Application, ed 3. London, SAGE, 2012.

18 Mechanic D: Sociological dimensions of illness behavior. Soc Sci Med 1995;41:12071216.

19 Sirri L, Fava GA, Sonino N: The unifying concept of illness behavior. Psychother Psychosom 2013;82:74-81.

20 Bech P, Rickels K: The items predicting nonremission after 6 months of treatment of patients with Generalized Anxiety Disorder covered the Eysenck neuroticism components of anxiety, interpersonal sensitivity and depression. Psychother Psychosom 2016;85: 229-230.

21 Bech P, Kessing LV, Bukh JD: The validity of dysthymia to predict clinical depressive symptoms as measured by the Hamilton Depression Scale at the 5-year follow-up of patients with first episode depression. Nord J Psychiatry 2016, Epub ahead of print.

22 Cosci F, Fava GA: The clinical inadequacy of the DSM-5 classification of somatic symptom and related disorders: an alternative trans-diagnostic model. CNS Spectr 2016;21:310-317.

23 Eysenck H, Fulker D: The components of type A behaviour and its genetic determi- nants. Act Nerv Super (Praha) 1982;3(pt 1):111-125.

24 Aronowitz RA: Making Sense of Illness. Cambridge, Cambridge University Press, 1998.

25 Vassend O, Skrondal A: The problem of structural indeterminacy in multidimensional symptom report instruments. The case of SCL-90-R. Behav Res Ther 1999;37:685-701.

26 Bech P, Bille J, Moller SB, Hellstrom LC, Ostergaard SD: Psychometric validation of the Hopkins Symptom Checklist (SCL-90) subscales for depression, anxiety, and interpersonal sensitivity. J Affect Disord 2014;160: 98-103.

27 Broderick JE, DeWitt EM, Rothrock N, Crane PK, Forrest CB: Advances in patient-reported outcomes: the NIH PROMIS ${ }^{\circledR}$ measures. EGEMS (Wash DC) 2013;1:1015.

28 Strupp HH, Horowitz LM, Lambert MJ (eds): Measuring Patient Changes in Mood, Anxiety, and Personality Disorders. Toward a Core Battery. Washington, American Psychological Association, 1997.

29 Rush AJ, Kraemer HC, Sackeim HA, Fava M, Trivedi MH, Frank E, Ninan PT, Thase ME, Gelenberg AJ, Kupfer DJ, Regier DA, Rosenbaum JF, Ray O, Schatzberg AF; ACNP Task Force: Report by the ACNP Task Force on response and remission in major depressive disorder. Neuropsychopharmacology 2006;31: 1841-1853.

30 Kyle PR, Lemming OM, Timmerby N, Soendergaard S, Andreasson K, Bech P: The validity of the different versions of the Hamilton Depression Scale in separating remission rates of placebo and antidepressants in clinical trials of major depression. J Clin Psychopharmacol 2016;36:453-456. 